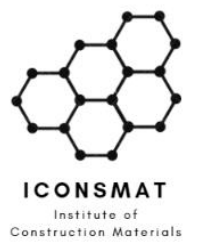

\author{
Content list available at ICONSMAT \\ Journal of Construction Materials \\ Journal homepage: www.iconsmat.com.au/publication
}

Article history:

Received 20 December 2019

Received in revised form

2 January 2020

Accepted 10 January 2020

Available online

2 April 2020

\title{
Entrepreneurship in the construction industry: How to succeed in the modern era
}

\author{
Amir Sartipi ${ }^{1}$ \\ ${ }^{1}$ Institute of Construction Materials, Tehran, Iran \\ Corresponding author: Amir Sartipi, Researcher, Institute of Construction Materials, Tehran, Iran. \\ E: amir.sartipi@iconsmat.com.au P: (+98) 09126710780
}

\begin{abstract}
In the modern context of management and entrepreneurship in the presence of wide access to information and high speed communication systems, an individual is able to accomplish multiple tasks those which might take a department to accomplish when it is compared to the classic concept of business operation. Digitalization, globalization, and robotics are just only a few of the factors that affect the business operation. Nevertheless, the importance of traditional knowledge/skills such as marketing, accounting, finance, and microeconomics is still in the place. A successful construction business in the modern era must be able to adopt the effective factors to the everlasting skill sets essential to a business. The current article is ought to adhere the modern technologies to the classical skill sets in a way to encourage the young generation to develop their entrepreneurship abilities. The uncertainties in the job market and the concern of full-time employment for young graduates are being addressed in the context of entrepreneurship. A survey had been conducted to clarify the status quo in a small population sample composed of small to medium size businesses in construction those are mostly operating in Australia. Recommendations had also been made in order to clarify the entrepreneurial path in the modern context of the construction economy.
\end{abstract}

\section{Keywords}

Construction; Entrepreneurship; Modern economy 


\section{Introduction}

The era of 2010 onwards, in general, had embraced a vast utilization of digital tools across the industries; construction not being an exception. Online retailers, social media, drone delivery, an autonomous cars are just a few of the highlighted digital technologies which had affected almost every industry. The emergence of these technologies, in fact, out fashioned the traditional/classic way of conducting business to a point. Marketing, accounting, finance, and microeconomics are the 4 most essential knowledge and skills that are required for operating a successful business. Although the concept of these four essential components are still unchanged but they have all undergone a significant change in terms of instruction. By definition, marketing is a set of skills for both promotion (push) and attraction (pull) of potential and loyal customers. Depending on the conditions of the marketplace, a marketing entity might align the strategies aiming to maximize the sales/customer engagement. Accounting, is the set of skills which is often confused by book keeping although it has more creativity inherited within. The management of assets, equities, and liabilities, preparation and the lodgment of tax reports are all amongst the responsibilities of an accounting firm. The department of finance in a firm, by definition is responsible to coordinate the expenditures throughout a specific timeframe by considering the interest rate and profit maximization as the main goals. The valuation of the company's asset and other relevant financial reports especially for public companies are another set of responsibilities that the department of finance is carrying out in a company. At last, and entrepreneur with the knowledge of microeconomics is able to evaluate the market condition and set the medium and long term strategies by considering the competition/collaboration in the market place.

Online retail as a substantiate result of advanced communication technologies had dressed up the modern era with such an edge that it is now taken as a fact that a business cannot be formed without a touch on digital techs. Although the term is general and expandable across the ranges of industries, the workflow is the same; customer places an order online, payment is made online in the following, the inventory is notified about the order, and a courier service arranges the pickup and delivery. Narrowing down to the application areas of online retail model in the construction industry, it can be discussed that the future of materials delivery and precast panels heavily relies on this model. As an example, upon the progress of this research no concrete batching plants had been found which would be capable of receiving online orders, despite the high opportunity of success and the ease of implementation. Precast fabrication on the other side, due to the high level of standardization and the high tendency for modular fabrication, is nevertheless an area which has the tremendous potentials of success once the online retailing model had been implemented. Regardless of the type of the product or services being delivered in this model, a well-established online business is featuring: (a) web-based ordering platform; (b) inventory management system; (c) secured payment gateway; (d) integrated courier service.

Social media marketing is the modern context of promoting a service/product is undoubtedly another crucial component of a modern construction firm. Although the digital environment had 
changed the means of delivering the promotional message to the customers, but the customer's decision making process is still the same: Need recognition (creating demand); Information search (visibility); Evaluation of alternatives (competitive edge); Purchase decision (availability); Post purchase behavior (loyalty). A construction firm firstly need to recognize the differences between marketing a service and marketing a product. This is mainly due to the intrinsic human nature that trusts tangible products much better and faster than intangible services. Subsequently, a marketing strategist after the recognition arranges decision making path for the customer in a way that ultimately leads the customer to the purchase decision in a timely manner. A marketing strategist in a building company which is expertizing in the delivery of high quality architectural and build process, is recognized as a service provider and requires its substantive marketing path. A steel manufacturer or a concrete batching plant (or more generally construction material retailers) are recognized as product delivery business which require their own substantive marketing path in that context. A digital marketing expert must employ the message delivery strategies based on the ways that humans receive information i.e. the goal is to influence the thoughts of potential customers digitally. Hearing, sight, and touch, are the three major senses that humans receive data upon. In other words, a digital marketing strategy must be arranged in such a way that creates an effective customer engagement by using these three senses. One other area of attraction for marketing departments in the modern era is the so-called green marketing which requires a precise focus for a starting business as there are more and more controls being imposed on the construction industry regarding its environmental performance[1].

Another emerging technology which is believed to influence the way to conduct business in the next decades is autonomous delivery vehicles. These systems with the integration of loT and the facilitation of $5 \mathrm{G}$ mobile networks are known to enhance the speed of project completion by lowering the number of labours involved and increasing the safety factors. In conjunction with the online retail business model, it is not far sighting to have a full automated robotic retail system which receives orders from the customer online and process the orders with the minimum human interaction[2]. Although fascinating in the concept, the social issues brought up by the implementation of these technologies are still subject to more investigations. From the social issues encountered is the transitional period of time from the current position to the point of time when the robots are fully taking over the delivery process. In such period confusion in the way humans bypass the interaction with robots is one of the controversial areas. Apart from the issues encountered with this emerging technologies, if thoroughly developed, a better chance of achieving higher safety at the construction sites as subsequent[3].

Nonetheless, as the global warming awareness is becoming more and more viral, governments and private entities are putting more focus on reducing the carbon foot prints [4, 5]. Construction industry as the second sector corresponding to a large amount of carbon emission after the energy sector, is subject to many controls. Thus, the managerial board in the newly established construction firms are urged to consider these controls [6-9]. 


\section{On Modern Economics}

The foundation of the modern economy is laid by John Maynard Keynes. His book called "General theory of Employment, Interest and Money" is a well-known reference in many top ranked universities across the globe. He had taken the supply driven demand (supply creates its own demand) as the axiom to his theory. Although outstanding in the history of economics, his theory lacks the consideration for the effect of robotics on the job market and employment. In fact, he had only considered the level of productivity in an economy as a factor of labor force available in the market. However, it is obvious that such assumption is invalid in the modern era as there are robots helping humans in completing the repetitive tasks. Further on, the Post-Keynesian theories had emerged in the following years aiming to address the existing gaps. One of the identical distinguishes for all these theories is the assumption of demand driven supply (demand creates its own supply).

The significance of economic considerations for entrepreneurs turns back to the principal of having a wise overview on the market trends, especially in terms of finance and employment. Meeting the organizational short term and long term objectives are nonetheless reliant on the evaluation of the managerial board i.e. where to invest and to what extend in order to maximize the gain? As an example on having a right overlook on the current situation, one of the phenomenal approaches in the recent years was the introduction of negative interest rates in the banking system in some capitalist countries.

In the recent years, capitalist governments such as United States and Germany (to a degree) decided to lower their federal interest rate to negative. According to the Reserve Bank of Australia The cash rate trend in Australia, following the alliance with capitalist economies in the financial context, had been decreasing. Error! Reference source not found. show the trend since 1990. The low interest rate close to zero is important to the large construction firms as it affects the employment and the propensity to consume. According to Fitch there are now 13 trillion dollars' worth of global sovereign debt trading in negative in interest rate [10]. The effect of negative interest in the housing market and real estate is in such a way that loan borrowers would be essentially getting paid from the bank for borrowing money. Governments decide to lower the interest rate once the economy is not performing well. This policy allows the individuals and investors to borrow money from the bank, increases the spending, and inspires more business initiatives. But one of the controversial consequences of such monetary policy is the subsequent high inflation since individuals purchasing power and the liquidity rate also increase. Nevertheless, a few European countries had adopted this policy in such a way that the inflation rate still records as less than $1.5 \%$ after several years. Although the adoption of this policy had shown economic growth in few countries, it is necessary to understand that there are prerequisites for implementing negative interest rate. Another argument that is present on rationalizing the reasons for embracing negative interest rate is essentially based on the criticisms to the existence of monetary policy at all. Modern economists believe that the so-called monetary policy 
(controlling the employment and wages via changing the federal interest rate) is no longer an applicable economic tool. Furthermore, another study done by Todhunter et al. [11] indicates that business must also consider the ruling political thinking in the international projects.

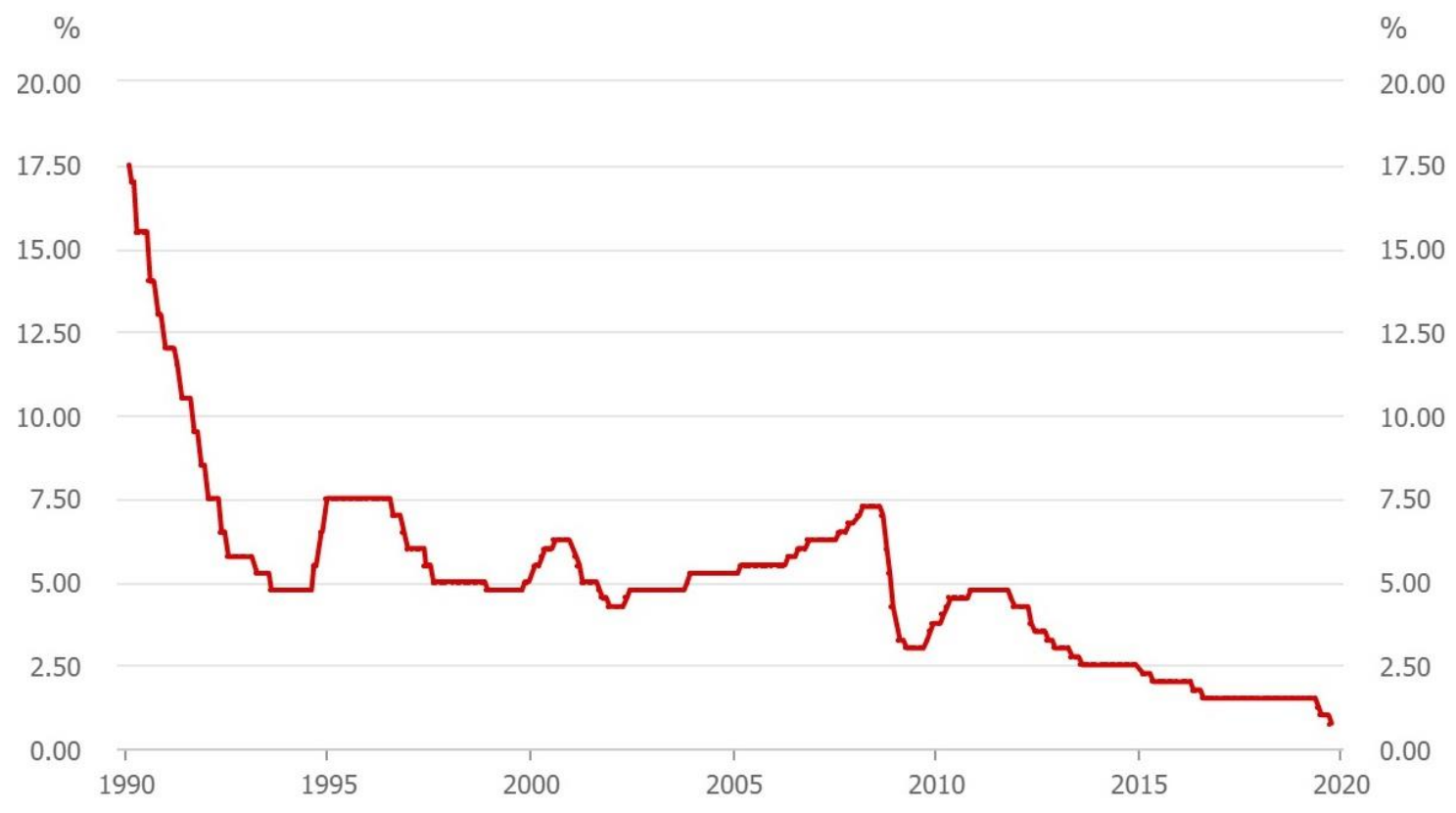

FIGURE 1 THE AUSTRALIAN CASH RATE THROUGHOUT THE HISTORY; DECREASING TREND IN THE FEDERAL INTEREST RATE [12]

Competition also, in a negative interest monetary policy, becomes a challenging topic. In most of the business models the competition is on attracting more customers. However, in an economy with a negative interest rate, banks will compete on decreasing the interest rate even further in negatives to satisfy more customers.

In the context of market performance for a specific good such as recycled aggregate, the effect of a present negative bank interest rate is significant since it derives motivation for small and medium size entities for conducting business in the flattened environmental cortex.

\section{Survey results}

In order to outline the current level of compatibility of the industry with the modern technologies, a question in the beginning of the survey had been asked subject to the last time that the participants completed an educational course. This will allow to understand whether the construction industry is concerned about academic engagement as a means of knowledge transfer 
and the way in which individuals are being acknowledged about the latest trends in the industry. Next, in order to outline the level of utilization of computer devices in the work place, a question had been asked subject to the number of hours that the individuals are using computer devices at

\section{Convinient way of remote comunication}

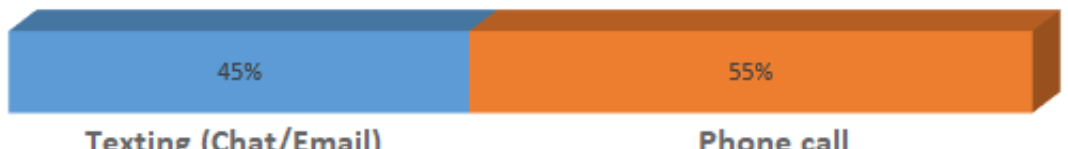

Hours working with computer

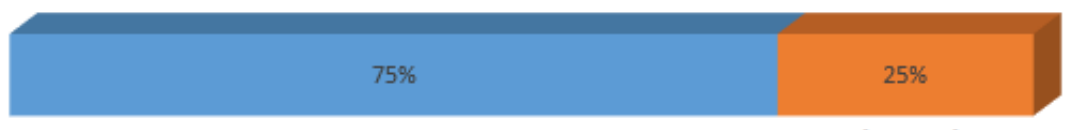

More than 3 hours

Less than 3 hours

Last time completed a degree

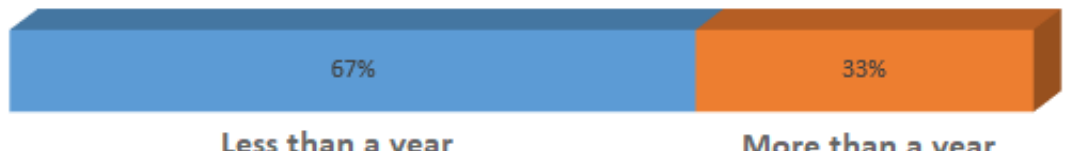

Less than a year

More than a year

FIGURE 2 SUMMARY OF THE SURVEY RESULTS

work per day. The results from this question will let know about the influence of digitization on the construction industry. At last, for the purpose of understanding the way in which individuals eager to communicate remotely a question had been asked subject to the favorite means of remote communication whether it is texting (chat or email) or phone calls.

An effort had been made to keep the questions as simple as possible to avoid confusion amongst the various classification of participants in the range of from uneducated labours to highly educated individuals.

From the results and aligned with the objectives of this research, three main recommendations can be expressed. Firstly, starting businesses must be focusing on creating a communication system (both for internal organizational cooperation and customer based cooperation) that receives and delivers the information via voice messages and text messages proportionally. Interestingly, Artificial Intelligence (AI) had introduced conversation between robots and humans throughout the voice recognition codes, although still at the basic levels. Furthermore, computer based operations is significantly appreciated in the period of years 2020-2030 as suggested by the responses. Care must be taken, however, in the essence of possible social harms caused by overworking with computer devices i.e. how does it change the human societies? At last, the Australian construction community had shown a great potential for embracing the latest 
technologies by responding a high level of engagement in the academic environment where most of the innovative technologies ignite.

The effect of technology is inevitable for starting a new business. This means that a starting construction firm must be equipped with the latest knowledge of computer science and electronics in order to secure the competitive advantage. From a review on the educational modules across the universities in construction courses, it can be realized that construction students are less equipped with the electronic and computer units.

The argument for the entrepreneurs in the construction sector is to shift its specialized labour force from a consumer of electronic devices and IT protocols into a rather producer of these technologies. It seems that currently the IT sector is sitting on top of all the other sectors of industry. This can be claimed as true since the top 3 largest companies by market value in 2019 are categorized as tech companies. In the same list published by Statista no construction company is found [13].

\section{Conclusion}

Construction entrepreneurs in the modern era must be able to create a competitive edge by developing computer aided platforms. This is crucial to the success of a business as the labour wages are high, robots are faster and more accurate, and also it is safer to have robots instead of humans at the construction sites where the level of health risks are normally high. Survey results had shown the necessity of having more computer-related modules within the universities' curriculum. The modern economic approach also adds another dimension. That is to consider the banking interest rate, and the level of employment. Further studies can reveal the mathematical correlation of technological advancements and the unemployment rate based on the Keynesian theory.

\section{Conflict of interest}

The author declares that the research was conducted in the absence of any commercial or financial relationships that could be construed as a potential conflict of interest. 


\section{References}

[1] W. Bevan and S.-L. Lu, "Green marketing in housing: reality or rhetoric?," Management, vol. 1243, p. 1252, 2013.

[2] T. Boulos, F. Sartipi, and K. Khoshaba, "Bibliometric analysis on the status quo of robotics in construction," Journal of Construction Materials, vol. 1, pp. 2-3, 2020.

[3] Q. Liu, G. Ye, and Y. Feng, "Workers' safety behaviors in the off-site manufacturing plant," Engineering, Construction and Architectural Management, 2019.

[4] W. Bevan, "An investigation of the required skills for the delivery of low and zero carbon buildings within a region," University of Reading, 2016.

[5] W. Bevan and L. Nolan, "Barriers for renewable technology in commercial buildings," 2019.

[6] A. Todhunter, M. Crowley, M. Gholamisheverini, and F. Sartipi, "Advanced technological implementation of construction and demolition waste recycling," Journal of Construction Materials, vol. 1, no. 1, 2019, doi: https://doi.org/10.36756/JCM.v1.1.3.

[7] F. Sartipi and A. Sartipi, "Recycling of coal mining slurry in concrete mortar," Journal of Construction Materials, vol. 1, no. 2, 2019, doi: https://doi.org/10.36756/JCM.v1.1.6.

[8] M. Gamil, A. Gharizadeh, and F. Sartipi, "A review on graphene reinforced cement composite: technical approach for ecofriendly construction," Journal of Construction Materials, vol. 1, no. 1, 2019, doi: https://doi.org/10.36756/JCM.v1.1.4. Institute of Construction Materials.

[9] A. Todhunter, M. Crowley, F. Sartipi, and K. Jegendran, "Use of the by-products of postcombustion carbon capture in concrete production: Australian case study," Journal of Construction Materials, vol. 1, no. 1, pp. 1-1, 2019, doi: https://doi.org/10.36756/JCM.v1.1.

[10] C. Whittall and S. Goldfarb, "Black Hole of Negative Rates Is Dragging Down Yields Everywhere," Wall Street Journal, 2016.

[11] A. Todhunter, M. Crowley, and F. Sartipi, "Construction productivity indices in socialism compared with capitalism," Journal of Construction Materials, vol. 1, no. 1, 2019, doi: https://doi.org/10.36756/JCM.v1.1.2.

[12] R. B. o. Australia, "Graph of cash rate," ed, 2019.

[13] The 100 largest companies in the world by market value in 2019 [Online] Available: https://www.statista.com/statistics/263264/top-companies-in-the-world-by-market-value/ 